\title{
Deficits in irregular past-tense verb morphology associated with degraded semantic knowledge
}

\author{
K. Patterson ${ }^{\mathrm{a}, *}$, M.A. Lambon Ralph ${ }^{\mathrm{a}}$, J.R. Hodges ${ }^{\mathrm{a}}$, J.L. McClelland ${ }^{\mathrm{b}}$ \\ ${ }^{a}$ MRC Cognition and Brain Sciences Unit, 15 Chaucer Road, Cambridge CB2 2EF, UK \\ ${ }^{\mathrm{b}}$ Center for the Neural Basis of Cognition, Carnegie Mellon University, Pittsburgh, PA, USA
}

Received 14 March 2000; received in revised form 22 September 2000; accepted 1 December 2000

\begin{abstract}
Two distinct mechanisms are often considered necessary to account for generation of the past-tense of English verbs: a lexical associative process for irregular forms like speak $\rightarrow$ spoke, and a rule-governed process ('add -ed') for regular and novel forms like talk $\rightarrow$ talked and wug $\rightarrow$ wugged. An alternative account based on a parallel-distributed processing approach proposes that one complex procedure processes all past-tense types. In this alternative view, neuropsychological dissociations are explained by reduced input from word meaning that plays a greater role in successful generation of the past-tense for lower frequency irregular verbs, and by phonological deficits that disproportionately affect regular and novel forms. Only limited evidence has been available concerning the relationship between knowledge of word meaning and verb-tense processing. The study reported here evaluated the past-tense verb abilities of 11 patients with semantic dementia, a neurodegenerative condition characterised by degraded semantic knowledge. We predicted and confirmed that the patients would have essentially normal ability to generate and recognise regular (and novel) past-tense forms, but a marked and frequency-modulated deficit on irregular verbs. Across the set of 11 patients, the degree of impairment for the irregular past-tense was significantly correlated with the degree of comprehension impairment as measured by verb synonym judgements. These results, plus other features of the data such as the nature of the errors to irregular verbs, are discussed in relation to currently developing theories of the language system. (C) 2001 Published by Elsevier Science Ltd.
\end{abstract}

Keywords: Semantic dementia; Progressive fluent aphasia; Regularisation errors

\section{Introduction}

A central aspect of human language is the ability to transform a word in some principled manner. Some common transformations occur across representational domains, for example from the orthographic to the phonological domain, as in reading aloud; others occur within a domain. In the morpho-syntactic realm that is the focus of interest here, the ability to transform the phonological form of a present-tense English verb (such as blink, drink or think) into its past-tense form (blinked, drank and thought, respectively) has attracted particular empirical and theoretical attention. The nature of the knowledge required to perform such trans-

\footnotetext{
* Corresponding author. Tel.: +44-1223-355294, ext. 870; fax: +44-1223-359062.

E-mail address: karalyn.patterson@mrc-cbu.cam.ac.uk (K. Patterson).
}

formations - how it is acquired by the child during language learning, how it is organised and expressed in the adult language system, and how it is disrupted by lesions to the adult brain - is a matter of considerable interest and debate in the fields of cognitive science, cognitive neuroscience, and linguistics.

Any account of this ability with respect to past-tense English verb morphology needs to explain successful transformations on three different classes of verb forms. Regular verbs, which constitute the substantial majority of the verb vocabulary $(86 \%$ according to Plunkett and Nakisa [34]), are turned into the pasttense by the addition of -ed (in orthographic form); in phonological form, this regular inflection is pronounced in one of three ways depending on the final phoneme of the base verb: / $\mathrm{t} /$ as in stopped, $/ \mathrm{d} /$ as in stared, and the syllabic combination of neutral vowel schwa $+/ \mathrm{d} /$ as in started. Irregular verbs, which include many of the 
most commonly used verbs in English, constitute the remainder of the established verb vocabulary, numbering somewhere around 164-180, depending on how one counts [17,31]. These irregular verbs form their pasttenses in a variety of different ways, including no change (hit $\rightarrow$ hit); single vowel alternations (eat $\rightarrow$ ate; drink $\rightarrow$ drank); terminal consonant phoneme changes (build $\rightarrow$ built, make $\rightarrow$ made); more complex phonological changes involving both vowel and terminal consonant (think $\rightarrow$ thought, sell $\rightarrow$ sold); and the odd high-frequency suppletive form ( $g o \rightarrow$ went, am $\rightarrow$ was). Finally, new words that enter the language ( $f a x)$ or even unreal words (plag) can readily be transformed into past-tense form, almost invariably by the addition of -ed, although occasionally by analogy with an irregular sub-grouping: is the past-tense of bling $\rightarrow$ blinged or blang? (the latter by analogy with sing $\rightarrow$ sang and ring $\rightarrow$ rang) (see [4] for evidence on the relative preferences of American speakers of English for blinged vs. blang).

The theoretical debate concerning past-tense verb morphology has largely centred on the question of how many mechanisms, one or two, are required to explain successful performance on these different classes of verb forms. According to the dual-mechanism account, a generative 'add -ed' rule provides a necessary and sufficient account of forming the past for regular verbs and novel forms; but since this procedure cannot deal with exceptions to the rule, an additional associative-memory mechanism is proposed for transforming take $\rightarrow$ took, bring $\rightarrow$ brought, etc. This view was introduced by Pinker [30] and has since been adopted and elaborated by several sets of authors (e.g. $[16,24,41])$; there is also a recent comprehensive formulation by its original proponent [31]. A contrasting view, framed in terms of parallel distributed processing (PDP), argues that all classes of past-tense transformation are achieved by a distributed, constraint-satisfaction process recruiting activation of the phonological and semantic representations of words. This account combines ideas drawn from the interactive activation model of word perception by McClelland and Rumelhart [23] and the model of past-tense formation by Rumelhart and McClelland [35]. It has likewise been endorsed and extended by other researchers, not only with reference to verb morphology $[17,22,33]$ but also in an account of the processes involved in translating orthography to phonology, i.e. reading aloud $[10,32,37]$.

The focus of the present investigation is neuropsychological dissociations in past-tense processing for different types of verbs. Following brain disease or injury, some aphasic patients have significantly better performance on regular than on irregular verbs, while other patients show the opposite dissociation. In traditional cognitive neuropsychology, a double dissociation is often considered proof for two separate mechanisms, and this has been the interpretation typically offered for evidence of a double dissociation in verb morphology. For example, in a comprehensive study, Ullman et al. [41] tested five different patient groups: three types of neurodegenerative disease (Alzheimer's disease [AD], Huntington's disease, and Parkinson's disease) plus two varieties of aphasic patient with vascular aetiology (those with anterior vs. posterior left-hemisphere lesions). The primary assessment involved a sentence completion task (e.g. "Every day I dig a hole. Just like every day, yesterday I _ a hole"). The posterior aphasic patients and a subset of the patients with AD were more accurate at generating the past-tense for both regular and novel verb forms than for irregular verbs. In contrast one anterior aphasic patient exhibited the opposite pattern, with a significant advantage for irregular verbs $(69 \%$ correct) relative to both regular $(20 \%)$ and novel forms $(5 \%)$. A subset of the patients with Parkinson's disease also revealed this version of the dissociation; and an additional five aphasic patients with large anterior lesions, who were unable to perform the sentence completion task, were more successful at reading aloud irregular than regular past-tense verbs. Ullman et al. [41] interpreted their results as supporting the dual-mechanism account, specifically arguing that the past-tense of irregular verbs is produced by a lexical-declarative process located in the temporo-parietal/medial temporal region, whereas the past for regular and novel verbs is generated by a procedural rule system encompassing frontal cortex and the basal ganglia.

A similar view was endorsed in a neuropsychological study by Marslen-Wilson and Tyler [24,25] involving a different technique. Control subjects and four aphasic patients made lexical decisions to spoken words preceded by spoken prime words with a varying relationship to the target item: semantically related nouns or adjectives (e.g. 'black' preceded by 'white'); irregular past/present verbs (e.g. 'give' preceded by 'gave'); and regular past/present verbs (e.g. 'call' preceded by 'called'). Normal subjects show significant priming (speeded lexical decisions) in all conditions. The performance of two agrammatic patients was facilitated in the irregular and semantic conditions but not for regular verbs preceded by their past-tense forms; indeed these patients suffered some interference or slowing in the regular past-tense condition. Two other patients, one with progressive aphasia and the other classified as agrammatic, exhibited the converse pattern: priming for regular verbs only.

Joanisse and Seidenberg [17] set out to demonstrate that neuropsychological dissociations like those reported by Ullman et al. [41] could be given a different interpretation. Their demonstration took the form of a constraint-satisfaction PDP model that employed distinct representations corresponding to the semantics 
and phonology of word forms, but lacked separate mechanisms for generating the past-tense by rule-governed and associative memory procedures. When 'lesioned' in different ways after training, the Joanisse and Seidenberg model produced both sides of the dissociation. Most germane to the topic of this paper, when damage affected the component of the model standing for semantic representations, the network exhibited a disproportionate deficit in generating irregular pasttense forms, and produced many regularisation errors. The explanation for this effect, from the perspective of the distributed, constraint-satisfaction framework, is as follows.

Producing a word in spontaneous speech corresponds to activating a phonological output representation from a semantic representation, which for a verb would include the semantic features of the action or state described by the verb, plus the relevant conditioning aspects that specify the appropriate inflection. Producing the past-tense form of a verb from a present-tense probe corresponds to generating a phonological output from a specification of the phonology of the presenttense, plus a partial semantic specification prompted by the instruction to produce the verb in its past-tense. Adult speakers of English have acquired the knowledge that enables them to perform the transformation task from a vocabulary consisting of both regular and irregular forms. This learning is assumed to result in a network that uses one common set of distributed phonological input and output representations and connections between these, and that is therefore sensitive to the systematicity of the present-past relationship across the vocabulary as a whole. Given that the great majority of English verbs form their past by addition of -ed, the transformation process will be strongly biased to produce the regular inflection as a default. Three main factors counteract this simple regular tendency.

First, as in all connectionist networks, learning is modulated by frequency of experience with specific patterns. Individual high-frequency irregular verbs (do $\rightarrow$ did, have $\rightarrow$ had) will therefore be well captured by the single process and suffer scarcely any interference from the army of regularly inflected verbs. This phenomenon results in the 'frequency-by-regularity interaction' that characterises the speed with which normal speakers perform past-tense transformations [36], in which it is only lower-frequency irregular items that are slowed relative to regular verbs.

A second factor that helps to offset the strong regular default is that a number of irregular verbs fall into clusters with respect to the relationship between present and past form. Processing of these items will benefit from neighbourly support, on a smaller scale than the pervasive regularity of $-e d$, but with more specific impact because of the high degree of phonological similarity among the members of each cluster (e.g. know $\rightarrow$ knew, blow $\rightarrow$ blew, throw $\rightarrow$ threw).
Some lower-frequency irregular verbs are left unassisted by either of these first two factors, but there is an additional constraint that can shift the balance in favour of the correct outcome: activation from semantics. Language processing must be characterised by constant and bi-directional communication between semantic and phonological components of the system, supporting both speech production and comprehension. Owing to the automatic nature of interactive activation between phonological and semantic representations, additional input from semantic knowledge about the word is assumed to enter the process of transforming a present-tense verb to its past for all verbs, no matter how frequent/infrequent or regular/exceptional. The claim, however, is that lower-frequency irregular verbs - the set of items least securely captured by the direct phonological transformation process - come to depend on this additional semantic source of constraint to an exaggerated degree relative to regular or higher-frequency verbs. The neuropsychological prediction is, therefore, that the verb processing of semantically impaired patients will reveal a selective deficit on irregular past-tenses, especially for less common verbs.

The purpose of the present communication is to consider additional data, from neurological patients, on the relationship between semantic impairment and knowledge of the irregular past-tense. Evidence for this relationship has been reported by Ullman et al. [41]: across their whole set of AD patients, the most anomic subset of whom showed a significant advantage for regular inflections in the sentence completion task, performance on irregular, but not regular, verbs correlated significantly with the patients' success on both an object naming task and a test of fact retrieval. Our reasons for seeking further observations on this issue included the following. First, although semantic memory does eventually tend to be compromised in $\mathrm{AD}[5,12]$, this is only one, and typically not the most prominent, of the cognitive deficits in AD. In patients with a different form of progressive memory and language disorder, known as semantic dementia [13,39], semantic knowledge is more selectively affected, and this patient group therefore seems particularly appropriate for investigating a direct link between such knowledge and success in processing irregular verbs. Secondly, as an extension of the demonstrated link between irregular-verb performance and semantic memory as measured by object naming or fact retrieval [41], it seems useful to relate patients' performance in past-tense verb tasks specifically to their level of knowledge of the meanings of the very same verbs. Thirdly, a crucial prediction of the connectionist framework is that the impact of disrupted semantic processing on irregular verbs should be significantly modulated by word frequency. To our knowledge, there are no published data that address this prediction. Finally, one of the most informative aspects 
of neuropsychological data is often the nature of incorrect responses. The performance of patients with semantic dementia in other somewhat similar tasks such as reading aloud led us to expect that their errors in past-tense verb generation were likely to be errors of commission rather than unrevealing omissions. If, as predicted, patients with semantic dementia were substantially impaired on irregular verbs, the resulting error corpus might provide additional constraints on theories of morphological processing and future modelling efforts.

\section{Methods}

\subsection{The neuropsychological disorder}

Semantic dementia is a neurodegenerative disorder associated with prominent atrophy of the inferior and lateral aspects of the temporal lobes $[13,26,39]$. The disorder is characterised by progressive, and eventually profound, anomia and comprehension impairment $[11,20]$. The disruption to conceptual knowledge typically extends beyond the realm of language to impairments of knowledge about objects and people [2], but it is semantic knowledge of words that is especially germane to verb processing. Until late in the progression of semantic dementia, there is little or no significant disruption to cognitive capacities that do not rely directly on semantic memory. In the domain of language, for example, the patients have relatively intact phonological and syntactic processing [3], and their auditoryverbal working memory as measured by digit span is within the normal range (see [28] for a fuller description of semantic dementia).

\subsection{Subjects}

\subsubsection{Patients}

The patients included in this study were 11 cases who fit the criteria for semantic dementia (as described by Hodges et al. [13] and Snowden, Neary and Mann [40]) and are part of a larger cohort of patients with dementia and/or progressive aphasia who have presented to a Memory and Cognitive Disorders Clinic at Addenbrooke's Hospital in Cambridge over the last few years. Some general information on the patients is presented in Table 1, where the 11 cases are arranged in approximate order from least (WM) to most (DG) semantically impaired, on the basis of clinical judgement as well as various test scores. Control data in this table come not from the 10 normal subjects specifically assessed on the verb tasks employed in this study (see Section 2.2.2 below) but rather from a group of 30 normal subjects (mean age $=68.5$, therefore on average a little older than the patients with semantic dementia, whose mean age $=61.5$ ). These normal participants were selected from the MRC Cognition and Brain Sciences Unit subject panel as controls for a study of cognitive deficits in Alzheimer's disease.

The first three test scores in Table 1 are from standardised neuropsychological tests, and reveal a picture of general mental status (MMSE) ranging from normal to definitely impaired, though with no severely demented cases; auditory-verbal working memory (digit span forwards) within the normal range for all 11 cases; and visuospatial skills (copy of the complex Rey figure) ranging from normal to clearly abnormal, but no cases with the kind of severe disruption that is often seen in AD [18].

The next two scores in Table 1 are from tests of naming and comprehension (word-to-picture matching) based on a 64-item subset of the Snodgrass and Vanderwart pictures [38]. For naming, each line drawing is presented individually for oral naming. For word-picture matching, each target picture is presented along with seven foils from the same semantic category; the name of the target item is spoken to the subject who is

Table 1

General background results for the $N=11$ patients with semantic dementia

\begin{tabular}{|c|c|c|c|c|c|c|c|c|c|c|c|c|}
\hline & WM & $\mathrm{SL}$ & $\mathrm{KH}$ & $\mathrm{AT}$ & AR & $\mathrm{VH}$ & $\mathrm{DM}$ & MB & IF & $\mathrm{JH}$ & DG & Control Mean (SD) \\
\hline Sex & $\mathrm{F}$ & $\mathrm{F}$ & M & M & $\mathrm{F}$ & $\mathrm{F}$ & M & $\mathrm{F}$ & $\mathrm{M}$ & $\mathrm{F}$ & $\mathrm{F}$ & \\
\hline Age & 51 & 49 & 58 & 64 & 66 & 75 & 62 & 65 & 64 & 60 & 63 & \\
\hline \multicolumn{13}{|l|}{ Test (maximum score) } \\
\hline MMSE (30) & 27 & 28 & 23 & 25 & 13 & 16 & 25 & 22 & 15 & 12 & 19 & $28.8(0.5)$ \\
\hline Digit span (forwards) & 8 & 6 & 6 & 8 & 5 & 8 & 8 & 5 & 6 & 7 & 5 & $6.8(0.9)$ \\
\hline Word-picture matching (64) & 64 & 60 & 58 & 57 & 54 & NT & 63 & 51 & 21 & 27 & 19 & $63.7(0.5)$ \\
\hline \multirow{2}{*}{$\begin{array}{r}\text { Pyramid and palm trees: pictures (52) } \\
\text { words (52) }\end{array}$} & 50 & 48 & 45 & 47 & 33 & 22 & 47 & 35 & 33 & 37 & 21 & $51.2(1.4)$ \\
\hline & 49 & 46 & 50 & 45 & 40 & 28 & 45 & 31 & 25 & 32 & 26 & $51.1(1.1)$ \\
\hline Synonym judgement (50) & 39 & 30 & 28 & 30 & NT & NT & 20 & 23 & 26 & 25 & 22 & $46.8(2.5)$ \\
\hline
\end{tabular}


Table 2

Numbers of different types of irregular verbs in the stimulus set

\begin{tabular}{|c|c|c|c|c|c|}
\hline Type of change & Examples & Main HiF & Main LoF & Ultra HiF & Total \\
\hline Vowel change & $\begin{array}{l}\text { eat } \rightarrow \text { ate } \\
\text { drink } \rightarrow \text { drank }\end{array}$ & 16 & 15 & 3 & 34 \\
\hline Consontant change & $\begin{array}{l}\text { have } \rightarrow \text { had } \\
\text { build } \rightarrow \text { built }\end{array}$ & 3 & 2 & 1 & 6 \\
\hline Suppletive & $\begin{array}{l}g o \rightarrow \text { went } \\
\text { am } \rightarrow \text { was }\end{array}$ & 0 & 0 & 3 & 3 \\
\hline Total & & 25 & 25 & 13 & 63 \\
\hline
\end{tabular}

asked to point to the corresponding picture. As indicated by the control scores, these are both very easy tests for normal individuals, and every patient other than the mildest (WM) was outside the normal range on both. The majority of cases were also impaired, some severely so, on the Pyramids and Palm Trees test of associative semantic judgements [15] which can be administered with triplets of either pictures or words (chance, 50\%). Table 1 ends with scores on a more taxing and sensitive semantic test of graded synonym judgements [43], on which every patient tested was outside the normal range and the last five cases did not manage to score above chance $(50 \%)$.

Magnetic resonance imaging revealed obvious temporal-lobe atrophy in all cases, most profound in the region of the temporal pole and the inferolateral temporal cortex. In virtually all cases, the atrophy was bilateral but highly asymmetrical, with $8 / 11$ cases having more prominent abnormality on the left; cases $\mathrm{KH}, \mathrm{VH}$ and DG in Table 1 are the exceptions, with more severe right-temporal atrophy.

The research reported here on past-tense verb processing was a cross-sectional study, and the indications of semantic status in Table 1 represent assessments done approximately at the time of the verb testing. These 11 cases are, however, enrolled in a more general programme of longitudinal assessment, and all have declined on our semantic measures since initial evaluation, confirming the progressive nature of the deficit.

\subsubsection{Controls}

The verb tests were also administered to 10 normal control subjects (seven men and three women from the MRC Cognition and Brain Sciences Unit subject panel), approximately matched to the patients for age and years of education.

\subsection{Stimulus materials}

For all three of the experimental tests described below, the principal stimulus materials consisted of 113 English verbs: a main set of 100 and a special set of 13 . In the main set, the verbs were divided into four conditions created by crossing two levels of regularity (regular verbs which are transformed into the past-tense by simple addition of $-e d$, and irregular verbs which form their past in some atypical fashion, described further below) with two levels of word frequency (high vs. low), creating 25 items in each of the four conditions. Because some of the most irregular verbs in English are also some of the commonest words in the language (items like do, go, have, give, etc.), the requirement to match regular and irregular items for frequency precluded use of these common verbs in the main set of 100 items. An additional 13 ultra-high-frequency irregular verbs, which have no regular counterparts in terms of word frequency, were therefore included as a special subset in each of the assessments.

The stimulus materials were designed to evaluate the main effects of verb frequency and regularity (and their interaction) on the patients' performance, not to assess the impact of the different ways in which irregular verbs form their past-tense (such as vowel change, terminal consonant change, no change, etc.). We therefore did not attempt to have equal proportions of these various types in our stimulus list. The relative numbers of each type in our set, indicated in Table 2, probably approximate the proportions of these types in the whole set of English irregular verbs.

All 113 verbs were monosyllabic in present-tense, and all $50+13$ irregular verbs were also monosyllabic in past-tense. Of the 50 regular verbs, 41 had a monosyllabic past-tense, while the other nine, all ending in $/ \mathrm{d} /$ or $/ \mathrm{t} /$ in present-tense, required an extra syllable to form the past(e.g. need $\rightarrow$ needed). 
Table 3 presents summary word statistics for the main set of 100 verbs, and demonstrates that within each frequency level (high vs. low), the regular and irregular verb sets were tightly matched on the first three measures: overall frequency of the uninflected form as calculated in the Kucera and Francis word frequency norms [19]; familiarity as rated on a 7-point scale in the MRC word database [6]; and imageability as rated in the same manner and from the same source. Note however that word frequencies in Kucera and Francis are not calculated separately for different parts of speech; many present-tense verbs in English can also be nouns (e.g. from our stimulus set, call, drink, play) or adjectives (e.g. warm, last, own), and the frequencies in this set of norms reflect the sums of all occurrences of the word, independent of how it is being used. On measures 4 and 5 in Table 3 - the frequencies of the uninflected form of the word specifically for its verb use, and of the past-tense form (from Francis and Kucera [7]) — the matching between regular and irregular subsets was less tight. Although close stimulus matching is always desirable, these discrepancies should not cause problems for the interpretation of our results, for two reasons. First of all, with a very few exceptions, words that can serve as both verbs and nouns (e.g. drink) or verbs and adjectives (warm) are closely and obviously related in meaning in their two different part-of-speech incarnations. It is possible that processing of a relatively infrequent verb like warm is in fact influenced by the much more frequent occurrence of

Table 3

Summary word statistics on the main set of 100 verbs, $N=25 /$ condition

\begin{tabular}{|c|c|c|c|c|}
\hline & $\begin{array}{l}\mathrm{HiF} \\
\text { regular }\end{array}$ & $\begin{array}{l}\mathrm{HiF} \\
\text { irregular }\end{array}$ & $\begin{array}{l}\text { LoF } \\
\text { regular }\end{array}$ & $\begin{array}{l}\text { LoF } \\
\text { irregular }\end{array}$ \\
\hline \multicolumn{5}{|c|}{ Freq uninflected form (Kucera and Francis, per million) } \\
\hline Mean & 215.2 & 215.6 & 21.6 & 21.4 \\
\hline Min & 67 & 61 & 1 & 1 \\
\hline Max & 772 & 794 & 62 & 58 \\
\hline \multicolumn{5}{|c|}{ Familiarity (ratings out of 700 ) } \\
\hline Mean & 572.2 & 581.3 & 530.7 & 527.2 \\
\hline Min & 518 & 529 & 453 & 438 \\
\hline Max & 613 & 628 & 594 & 586 \\
\hline \multicolumn{5}{|c|}{ Imageability (ratings out of 700) } \\
\hline Mean & 463.5 & 462.8 & 464.0 & 464.6 \\
\hline Min & 327 & 322 & 323 & 299 \\
\hline Max & 588 & 585 & 598 & 599 \\
\hline \multicolumn{5}{|c|}{ Freq verb present (Francis and Kucera, per million) } \\
\hline Mean & 36.2 & 176.6 & 7.5 & 15.8 \\
\hline Min & 0 & 6 & 0 & 1 \\
\hline $\operatorname{Max}$ & 160 & 791 & 53 & 57 \\
\hline \multicolumn{5}{|c|}{ Freq verb past (Francis and Kucera, per million) } \\
\hline Mean & 24.3 & 137.8 & 7.3 & 16.3 \\
\hline Min & 0 & 7 & 0 & 1 \\
\hline $\operatorname{Max}$ & 165 & 618 & 46 & 65 \\
\hline
\end{tabular}

this word, with its highly related meaning, as an adjective. Secondly, for specific verb use, the irregular forms in our study were significantly higher in frequency than the 'matched' regular verbs (present-tense: $t=$ 3.14, $P<0.01$; past-tense: $t=3.05, P<0.01$; see Table $3)$. This direction of difference should reduce rather than increase our predicted disadvantage for irregular verbs in the patients' performance.

In addition to the 113 real-word verbs used in all three verb tasks, subjects were also assessed on two of the three tasks (generation and forced-choice recognition of the past-tense) with 'novel' verbs: the 20 nonword items devised by Ullman et al. [41] (e.g. spuff, dotch, vask, tunch).

\subsection{Tasks}

\subsubsection{Generation of the past-tense}

On each trial, the subject was presented with a sentence using the target verb in present-tense (e.g. "Today I think about my friend") followed by a request to fill in the gap in the same sentence presented in a form that requires the past-tense ("Yesterday, I __ about my friend"). Although patients with semantic dementia typically have unimpaired auditory verbal working memory, and therefore should not have any difficulty holding on to spoken versions of the sentences, we wanted to provide the patients with the maximum information and opportunity to provide the correct response; therefore, as well as hearing the sentences spoken by the experimenter, subjects were concurrently given a written version of each sentence pair to look at, with an underlined gap in the second sentence where the past-tense should be supplied. All 113 real-word verbs were embedded in sentences with some sort of semantic elaboration ("Today I think about my friend"; "Today I type a letter"; etc.). In the case of the 20 novel items, the generation task used an unelaborated sentence frame, e.g. "Today I spuff. Yesterday I _ ".

\subsubsection{Two alternative forced choice (2AFC) recognition of the past-tense}

For each target verb, the subject was presented (in both spoken and written form) with the same presenttense sentence as used in the generation task. The experimenter then read aloud the second sentence of each pair, offering two spoken choices at the verb position. For example, "Today I think about my friend. Yesterday I thought? or thinked? about my friend". The correct alternative was offered first in half of the trials and second in the other half. Visual presentation of the sentences was identical to that in the generation task, with the past-tense verb in the second sentence of each pair omitted and represented by an underlined blank; thus the two response choices were offered only in 
spoken, not written, form. This procedure was adopted to make the task have somewhat less the character of a lexical decision experiment: with visual presentation of the choices, the subject would have been offered two written items, one of which was a familiar word (e.g. thought) and the other typically a non-word (thinked). It would be possible, of course, to treat the task as auditory lexical decision; but lexicality should serve as an additional cue for the subject to choose the correct response and thus bias the results against observing the predicted deficit.

For the recognition task, the incorrect choice for all of the $50+13$ irregular verbs in the study was the regularised -ed form (buyed, thinked, goed, sleeped, etc). As foils for the regular verbs, we attempted to create phonological forms that resembled the presenttense regular target words in ways somewhat similar to those relating existing irregular past-tenses to their present forms. Most therefore consisted of a vowel change (e.g. for the regular verb save, the foil was 'sove', somewhat analogous to drive $\rightarrow$ drove; for shape, the foil was 'ship', somewhat similar to slide $\rightarrow$ slid). This procedure of changing the vowel, in the phonologically dense neighbourhood of monosyllabic words in English, inevitably meant that some of the foils for regular words (like ship) were real words. Note that at least some of the foils in the irregular condition were also real words (e.g. 'seed' as the regularised past-tense foil for see is a word, and 'buyed' is a homophone of the word 'bide'), but we acknowledge that there was a higher proportion of real-word foils for the regular than the irregular condition. This imbalance should not be problematic because its effect, if any, should once again bias the results against the predicted outcome: choosing between two phonologically familiar response choices ('shaped'/'ship') might well prove harder than selecting between two alternatives of which only one has lexical phonological status ('thinked'/'thought'), whereas our prediction was of a selective difficulty with the irregular forms.

Foils for the novel items from Ullman et al. [41] were created in a similar fashion to the foils for the real regular verbs, i.e. by constructing a phonologically related alternative that resembled the presenttense in some realistic way such as a vowel change (e.g. "Today I dotch; yesterday I dotched? or datch?').

\subsubsection{Synonym judgements on the present-tense verbs}

Although our longitudinal investigations of these patients provide a variety of measures for assessing the extent of their semantic deficits, one of the purposes of this study was to relate the patients' performance in generating and recognising the correct past-tense to a comprehension assessment based on the same verb materials. We therefore devised a
2AFC synonym judgement task, in which the subject was given the present-tense of each of the 113 verbs and asked to choose one of two other present-tense verbs as similar in meaning to the target. One of the choices was an approximate synomym; the other was unrelated in meaning (for example: target = grind; 'synonym' $=$ crush; foil $=$ sip $)$. Targets and response choices were presented in both spoken and written form, and the order of correct and incorrect choices was counterbalanced over trials. Because some or indeed many verbs in English can also be nouns or adjectives, the verb-ness of the stimulus items (which of course is apparent when the words are presented in a sentence context) was emphasised in this single-word synonym judgement task by the experimenter's verbal presentation, which was to say 'to grind: does that mean to crush or to sip?'. The synonym judgement task was of course administered only with the 113 real-word verbs, not with the 20 novel (non-word) items.

\subsection{Procedure}

For each task, the main block of 100 verbs, corresponding to a random order of the stimulus items in this set, was preceded by a small set of practice items (some regular and some irregular verbs) not used in the test proper. The subject was allowed to go through these practice items as many times as necessary in order to get the correct idea. For all control subjects and the majority of patients, the instruction and a single example would have been sufficient, but a few of the most impaired patients needed more extended practice. The 13 ultra high frequency irregular verbs were tested as a separate block in each of the three tasks, immediately after the main set of 100 and therefore not requiring additional instruction. The 20 novel items were also administered as separate blocks in the two tasks for which they were appropriate (generation and forced-choice recognition), in each case following the word tasks.

Control subjects were tested in the same manner as the patients, with one exception designed to avoid unnecessary waste of testing time. We anticipated (correctly) that almost all controls would achieve perfect or near perfect scores on the past-tense verb generation task with real words, and furthermore that the occasional error by a normal subject would likely fall in the lower-frequency half of the main set of 100 verbs. We therefore set a criterion in advance that each control would be assessed on the easier forcedchoice recognition version of the past-tense task only if he or she made three or more errors (out of 100) in the generation test, and then would only be given the 50 lower-frequency items for $2 \mathrm{AFC}$ recognition. 


\section{Results}

\subsection{Control group}

It has been established by previous research [36] that when normal adult speakers are asked to generate the past-tense of English verbs, their response times reveal a frequency-by-regularity interaction, with significantly slower correct responses to low-frequency irregular items (e.g. stride $\rightarrow$ 'strode', weep $\rightarrow$ 'wept') than to the other three conditions. Our goal for control performance in this study was merely to measure accuracy amongst a small group of normal speakers from the same population as the patients, in order to define a standard of normal performance against which the patients' success could be evaluated. As expected, the control participants achieved virtually perfect scores on all assessments. For the 13 ultra-high frequency verbs, every one of the 10 controls scored $100 \%$ on both past-tense generation and comprehension (2AFC synonym judgements). For the main set of 100 verbs, mean control accuracy was $99.4 \%$ on the synonym judgements and $98.4 \%$ on the generation task. Of the 10 controls, one individual made three errors in generation and two further participants made four errors each. Forced choice recognition (on the 50 lower-frequency verbs) was therefore assessed for these three subjects, whose scores for selecting the correct past-tense in $2 \mathrm{AFC}$ were $50 / 50,49 / 50$ and $48 / 50$. The three recognition errors by these latter two control subjects were in fact on different items from the ones on which they had erred in the generation task.

Of the 16 total errors (out of 1000 responses: 10 subjects $\times 100$ items) by normal subjects in the main generation task, all were from the lower frequency set of words, with 12 to irregular and four to regular verbs. The four regular errors were all cases of reproducing the present-tense in place of the past on a verb that, in its present-tense, ends in $/ \mathrm{t} /$ as many past-tense forms do: for example, two subjects produced sweat $\rightarrow$ 'sweat'. Of the irregular errors, the most common error type made by the patients (see below) was extremely rare for normal subjects. This error, which is the simple addition of -ed to an irregular verb stem and which we shall label a 'pure regularisation', occurred only four times out of all responses by control participants $(2 \times$ bet $\rightarrow$ 'betted', $2 \times$ flee $\rightarrow$ 'fleed'). The remaining eight mistakes all occurred to irregular verbs that have a short /I/ vowel and form their past by changing this vowel either to /ae/ (swim $\rightarrow$ swam, sink $\rightarrow$ sank, spring $\rightarrow$ sprang) or to $/ \wedge /$ (sting $\rightarrow$ stung, string $\rightarrow$ strung); every one of these eight errors was to produce the other one of these two vowel options (e.g. $\operatorname{sink} \rightarrow$ 'sunk', sting $\rightarrow$ 'stang').

For the 20 novel items, the majority of the control subjects' generation responses, as expected, consisted of
Past tense generation

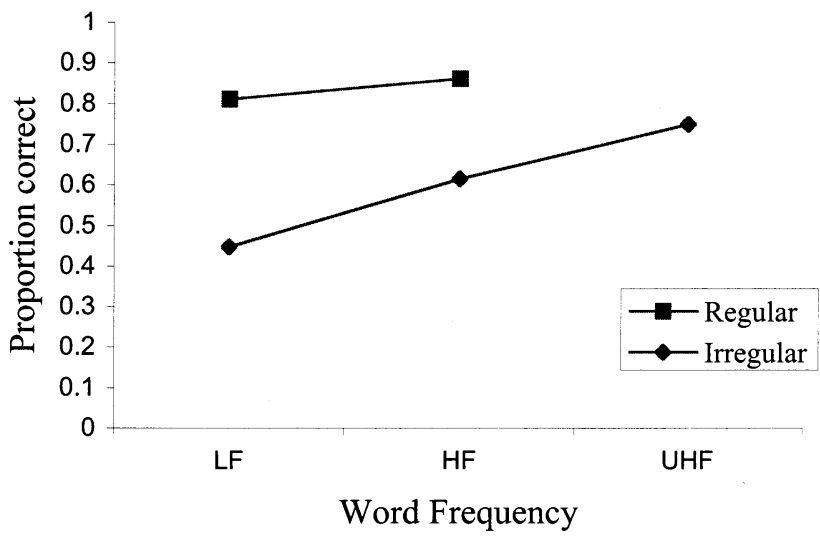

Fig. 1. Mean performance for the group of patients $(N=11)$ for each of the five conditions of real-word verbs (low-frequency regular, high-frequency regular, low-frequency irregular, high-frequency irregular, ultra-high-frequency irregular) for the task of generating the past-tense.

adding -ed $($ mean $=19 \cdot 1 / 20)$. One control subject adopted the occasional strategy of changing the vowel in generating a past-tense to a novel verb (e.g. scash $\rightarrow$ 'scush'), and thus produced only 15/20 -ed responses.

Having established that normal adult speakers (from the same population as the patients assessed here) achieve nearly flawless success on the verb tasks employed, we turn our attention to the patients. Their results will be organised in three sections covering: (1) accuracy of generating and recognising past-tense verb forms; (2) the nature of the errors in generating the past-tense of irregular verbs; and (3) the relationship between verb comprehension and both past-tense generation and recognition.

\subsection{Patients}

\subsubsection{Accuracy in generating and recognising the past-tense of real verbs}

\subsubsection{Effects of frequency and regularity. Fig. 1 and} Fig. 2 present the average accuracy of the 11 patients in generating (Fig. 1) and recognising (Fig. 2) the pasttense of the main set of verbs, in four conditions created by crossing frequency with regularity, plus the extra set of ultra-high frequency irregular verbs. The functions for the two tasks look very similar, although performance (especially for the lower curve in each, corresponding to the irregular verbs) was unsurprisingly better in the recognition than the generation task. Accuracy was markedly poor on the irregular verbs: for the lowest frequency band of these items, the group average for past-tense generation $(\approx 0.45$ correct) contrasts with accuracy of better than 0.95 for the control subjects; and although the patients were more success- 
ful when offered a recognition choice between the correct and regularised past-tenses, they still (as a group) achieved only an average $\approx 0.65$ proportion correct on these lower-frequency irregular items in a task where normal performance is virtually 1.00 and chance is 0.50 .

Analysis of variance on the main set of 100 items, which consisted of equal-sized and frequency-matched sets of regular and irregular verbs (i.e. excluding the 13 ultra high irregular items), revealed a frequency effect, a regularity effect and an interaction between these two variables. For the generation task, all of these effects were significant in the analysis both by subjects (frequency: $\quad F_{\mathrm{s}}(1,10)=15.5, P<0.01 ; \quad$ regularity: $F_{\mathrm{s}}(1,10)=15.5, \quad P<0.01 ; \quad$ interaction: $\quad F_{\mathrm{s}}(1,10)=$ $8.9, P=0.01)$ and by items (frequency: $F_{\mathrm{i}}(1,96)=$ $14.4, P<0.01 ; \quad$ regularity: $F_{\mathrm{i}}(1,96)=112.7, P<0.01$; interaction: $\left.F_{\mathrm{i}}(1,96)=4.1, P<0.05\right)$. For the recognition task, the two main effects were reliable both by subjects (frequency: $F_{\mathrm{s}}(1,9)=22.3, P<0.01$; regularity: $\left.F_{\mathrm{s}}(1,9)=18.3, P<0.01\right)$ and by items (frequency: $F_{\mathrm{i}}(1,96)=6.3, P=0.01 ; \quad$ regularity: $\quad F_{\mathrm{i}}(1,96)=$ $67.8, P<0.01)$ but the interaction did not achieve significance (both $F$ 's $<1$ ). [Note that the degrees of freedom for the by-subjects analysis of the recognition task are 1,9 rather than 1, 10 because we were unable to collect forced-choice data from one patient, who became untestable for other reasons during the course of this study.]

With reference to the data in Fig. 2, the patients could be described as having near normal success in recognising the correct past-tense of regular verbs (mean proportions of 0.90 and 0.93 correct, respectively, on the lower and higher-frequency regular

\section{Past tense recognition}

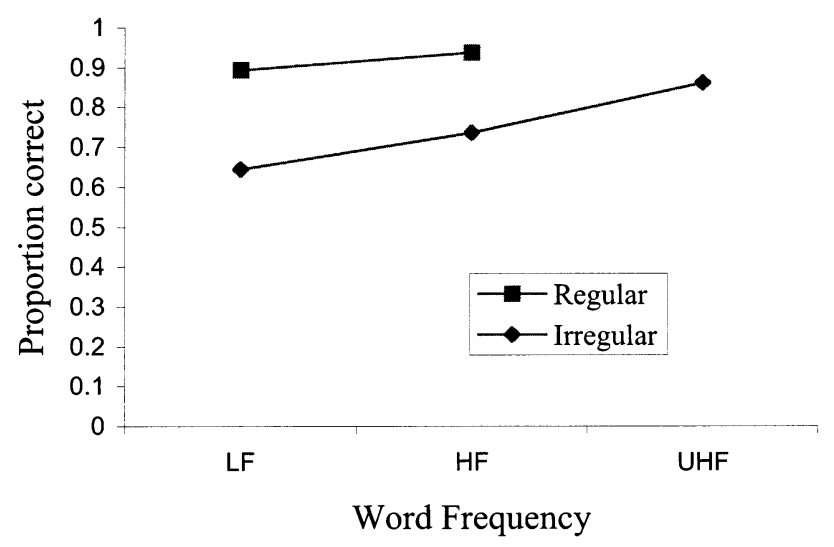

Fig. 2. Mean performance for all patients for each of the five conditions of real-word verbs (low-frequency regular, high-frequency regular, low-frequency irregular, high-frequency irregular, ultra-highfrequency irregular) for the task of recognising the correct past-tense in a two-alternative forced choice test. Note that we were unable to obtain 2AFC recognition data for one case, with the result that $N=11$ patients for Fig. 1 but $N=10$ for Fig. 2 . items); but in the generation task (Fig. 1), average group performance on the regular items was clearly subnormal even if significantly better than for the irregular verbs. This abnormality on the regular verbs was, however, entirely attributable to three of the 11 patients, whose scores have been included in all of the data thus far presented but who probably should be excluded from group performance on the generation task, because these three (each in a slightly different fashion, see Section 3.2.1.2 below) failed to comply with the generation task instructions. In the group averages with these three cases excluded, past-tense generation performance was preserved on regular verbs. Means for the remaining eight cases are: low-frequency regular $=0.96$, high-frequency regular $=0.98$, low-frequency irregular $=0.53$, high-frequency irregular $=0.71$ (ultra-high frequency irregular $=0.82$ ). These results provide striking confirmation of a deficit restricted to irregular verbs.

Certainly the subset of $N=8$ but even the full set of $N=11$ patients provide more convincing evidence of a selective deficit for irregular verbs than any previously reported cases. Ullman et al. [41], for example, considered the results for their groups (both $N=5$ ) of AD and posterior aphasic patients to constitute support for this dissociation: the mean scores of these two groups on regular vs. irregular verbs were 0.89 vs. 0.60 and 0.83 vs. 0.71 correct. These differences were both statistically significant and are therefore relevant evidence; but the degree of both preservation for regular and deficit for irregular verbs was less dramatic than the dissociation in our group of patients with semantic dementia. Furthermore, our results demonstrate the marked impact of word frequency on success in generating the past-tense of irregular verbs.

\subsubsection{Performance of three patients who did not/could} not comply with instructions in the generation task. Patient AR (whose degree of semantic degradation was moderate but not severe) often could not be persuaded to give inflected past-tenses: her preferred response in this task, despite numerous examples of appropriate past-tense responses, was 'did X' (e.g. "today we send her flowers, yesterday we did send her flowers"). Although this is a kind of past-tense reply, it does not represent an attempt to produce an inflected form of the verb and so was scored as an error. AR made this form of response almost as frequently to regular verbs as to irregular items, with the result that she was very significantly impaired on the regular verbs and showed only a minimal advantage for regular $>$ irregular $(29 / 50$ vs. 21/50 correct).

Patient JH (whose degree of semantic decline was severe) also had substantial difficulty in complying with the generation task instructions. Her initial inclination was to try to supply a different verb stem to complete 
the past-tense version of the sentence; when told by the experimenter that she should use the 'same word' as in the present-tense sentence, she over-complied with this instruction and just repeated the uninflected presenttense verb on many trials (e.g. "Today I eat soup for lunch, yesterday I eat soup for lunch"). Her score on the regular verbs $(31 / 50$ correct $)$, although better than for the irregular ones $(18 / 50)$, was clearly much poorer than that of normal subjects, or indeed most of the patients, due to this strong tendency to reproduce the present-tense.

Patient DG had the most severe semantic deficit of all 11 patients tested here. As it happens, she was the very first patient in the series to be tested on these verb tasks, and was given an initial version of the generation task that was subsequently modified on the basis of her performance. In this initial version, to provide variation from the repetitive "Today I..., yesterday I...", we had created some sentences of the form "Today he grinds the coffee, yesterday he...", or "Today she wears a coat, yesterday she...". DG, who could not get the idea of transforming the verb from present to past-tense, adopted the response strategy of removing the $-s$ from any present-tense verb that contained one, and adding an $-s$ to any that did not. She employed this strategy so consistently that she scored a mere $10 / 50$ correct on the regular verbs and $5 / 50$ on the irregular items. For all subsequent testing, we revised the sentences to include only 'I', 'we' and 'they' as pronoun subjects of the sentences, thus avoiding any present-tense verbs ending in $-s$.

3.2.1.3. Non-words. Although our main interest was in the distinction between regular and irregular real words, we also tested the ability to generalise to novel forms. We were unfortunately unable to obtain nonword test results from two of the 11 cases, simply because of limited testing time, not because these two patients were unable to do the task. Of the nine cases tested, seven generated base + -ed for every one of the 20 novel items and also selected the base + -ed form in $2 \mathrm{AFC}$ recognition for every novel item. Of the remaining two cases, JH (who, as indicated in Section 3.2.1.2, was very semantically impaired) responded to $7 / 20$ nonwords in the same manner of her responses to many real words in the generation task, by reproducing the present-tense form; she thus produced only 13/20 -ed responses to novel verbs, although she selected the base $+-e d$ option for 19/20 novel items in forced choice recognition. AT, who had mild semantic degradation and performed flawlessly $(50 / 50)$ in generating the pasttense of real regular verbs, somehow seemed to think that $-e d$ responses were too simple for the non-words, and produced vowel changes for $7 / 20$ of these items (e.g. "Today I plag, yesterday I pleg"). Normal subjects very occasionally make this kind of response, too.
Table 4

Proportion correct in generating the past-tense of irregular verbs (collapsed across low, high and ultra-high frequency) as a function of type of change that the present-tense undergoes to become past-tense

\begin{tabular}{llll}
\hline Type of change & Examples & $N$ verbs & $\begin{array}{l}\text { Proportion } \\
\text { correct }\end{array}$ \\
\hline $\begin{array}{l}\text { Vowel change } \\
\begin{array}{l}\text { Vowel + consonant } \\
\text { change }\end{array}\end{array}$ & $\begin{array}{l}\text { eat } \rightarrow \text { ate } \\
\text { lose } \rightarrow \text { lost }\end{array}$ & 34 & 0.55 \\
$\begin{array}{l}\text { Consonant change } \\
\text { No change }\end{array}$ & make $\rightarrow$ made & 6 & 0.62 \\
Suppletive & hit $\rightarrow$ hit & 6 & 0.76 \\
go $\rightarrow$ went & 3 & 0.33 \\
\hline
\end{tabular}

3.2.1.4. Different types of irregular verb. As noted in Section 2.3, the type of irregular verb (i.e. the phonological relationship between past and present: vowel change, terminal consonant change, etc.) was not a principal manipulation in this study, and the unequal numbers of the different types limit our ability to assess the impact of this variable. Nevertheless, we offer the following intriguing speculation about the patients' success on irregular verbs as a function of change type, displayed in Table 4. Irregular verbs which are transformed into the past-tense via a change in terminal consonant (either on its own, as in make $\rightarrow$ made, or in combination with a vowel change, as in tell $\rightarrow$ told) always result in a past-tense form with either a final $/ \mathrm{t} /$ or a final $/ \mathrm{d} /$, resembling the phonological changes associated with the regular -ed past-tense. In a sense, therefore, these items might be considered to represent a kind of intermediate case between regular verbs that add a final $/ \mathrm{t} /$ or $/ \mathrm{d} /$ and more frankly irregular verbs, e.g. those requiring unpredictable vowel changes. Despite the small numbers of items, the trend towards greater success by the patients in generating past-tense forms involving just a change in the terminal consonant (mean proportion correct $=0.76$ ) relative to vowel changes (0.55) seems to fit this idea, as does the fact that performance on the vowel + consonant change items (0.62) fell in between the consonant-only and vowel-only changes. The relatively good performance on the few suppletive forms might seem to contradict this notion of graded performance on irregular verbs as a function of the similarity of their phonological changes to that in regular verbs. Recall, however, that there were only three of these items and all came from the ultra-high frequency subset on which performance was generally much improved.

\subsubsection{Analysis of errors in generating the past-tense of irregular verbs}

Table 5 provides a description, examples, and proportions of each of the main error types that the patient group made to irregular words in the past-tense generation task. The proportions are given not only for the 
whole set of patients $(N=11)$, but also $(N=8)$ excluding the three patients $\mathrm{AR}, \mathrm{JH}$, and $\mathrm{DG}$, each of whom adopted a generation strategy resulting in highly atypical errors to both regular and irregular words. The effect of including/excluding these three cases can readily be seen in Table 5 by comparing the proportions of pure regularisation errors and 'other' errors for the two analyses: with the three non-instruction-compliant cases excluded, the rate of regularisation errors increased by about $25 \%$ and the rate of 'other' errors decreased by about the same amount.

As expected, the most common error type was a pure regularisation, even averaged over all 11 patients and especially for the eight cases who were able to follow task instructions. This presumably reflects the overwhelming likelihood that a verb in the English language will form its past-tense by the addition of -ed to the stem. Thus when some process crucial to knowledge of irregular pasts is impaired, the strong default of -ed emerges. Although the two principal contending accounts of past-tense processing may disagree on what this impaired process is, both would expect its disruption to yield a preponderance of regularisation errors. Error types 2, 3 and 4 in Table 5 may therefore be more informative about the possible underlying mechanism.

The majority of errors in category 2 (like tear $\rightarrow$ 'tored') were a straight combination of the correct past transformation $+e d$, although there were also some more complicated cases (like sleep $\rightarrow$ 'sleepted') where the response suggests only partial knowledge of the irregular past (i.e. that it requires addition of $/ t /$ ) plus the default $-e d$. Category 3 errors consisted of vowel changes just like those that characterise the relationship between present- and past-tense for other real irregular verbs: the vowel alternation in slide $\rightarrow$ 'slode' is like that in write $\rightarrow$ wrote; the vowel change in read $\rightarrow$ 'raid' is like eat $\rightarrow$ ate; and the change from slit $\rightarrow$ 'slat' is analogous to sit $\rightarrow$ sat. Category 4, reproducing the present-tense form as past, may seem a less telling error type since the patient has not transformed the stimulus; but interestingly, virtually every instance of this error type (apart from those produced by patient $\mathrm{JH}$, who had adopted no-change as her default strategy throughout the generation task) occurred in response to a present-tense verb that ends in $/ \mathrm{t} /$ (like eat) or /d/ (like grind). The importance of this observation is that it is only $/ \mathrm{t} /$ - and $/ \mathrm{d} /$-final verbs that take no change as their correct past tense forms (e.g. let $\rightarrow$ let and bid $\rightarrow$ bid). Possible implications of these three error types will be addressed in the Section 4 .

\subsubsection{The relationship of past-tense processing to semantic impairment}

Although several different measures of semantic impairment could be employed to address this issue, the most directly relevant one is the patients' comprehension of the same present-tense verbs for which they were asked to generate and recognise the past-tense, that is, the 2AFC synonym judgement task. The patients were, as a group, substantially impaired on this test, with an average proportion correct of 0.75 (controls' performance $=0.99$; chance $=0.50$ ). Otherwise, there is little of interest to say about synonym performance per se, since the variables of interest that characterise skill in past-tense generation and recognition do not apply to comprehension. For example, there would be no reason to expect verbs that take regular vs. irregular past-tense forms (but are matched in other regards) to yield differential rates of success in synonym judgements on the present-tense form of the verb, and

Table 5

Analysis of error types in the generation task for all 50+13 irregular verbs (i.e. summed across the three levels of word frequency and the different types of irregular verb such as vowel change, consonant change, etc.): (i) for all 11 patients; (ii) without the three cases who did not/could not attempt to produce the past-tense

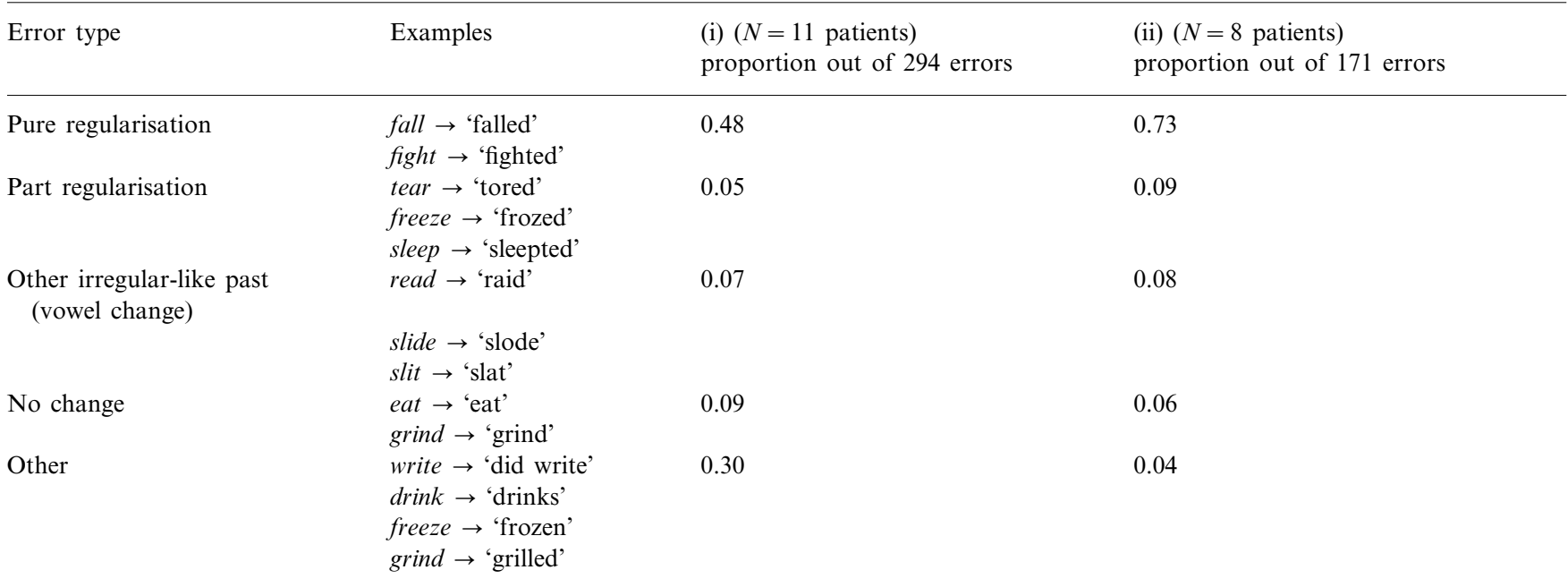


they did not: the patients achieved identical scores $(0.75)$ on the two 50 -item subsets of regular and irregular items. Accuracy also did not differ significantly as a function of verb frequency (high $=0.77$; low $=0.73$ ). This might seem surprising, since the decline of receptive as well as expressive vocabulary in semantic dementia is known to be modulated by frequency [8]. It must be recalled, however, that correct responses in the synonym judgement task require comprehension of the response choices as well as the target words. Given the difficulty of finding satisfactory synonyms at all for many verbs, we had made no effort to manipulate or match word frequencies for the response alternatives, and thus would not predict an effect of target word frequency in this task.

The important result concerning synonym-judgement performance is not its own characteristics, which are sparse, but its relationship to the patients' success in both generating and recognising the pasttense. Our prediction was that, if the patients are rank ordered from best to worst on synonym-judgement scores, their corresponding past-tense scores should decline markedly for irregular but not for regular verbs.

3.2.3.1. Past-tense generation in relation to synonym judgements. Fig. 3a displays each patient's past-tense generation score for the regular and for the irregular verbs in the main set (range of possible scores from 0 to 50 in each case) in relation to his or her synonym score (range of possible scores from 50, which equals chance performance, to 100). The best linear fit to each function is also included. Fig. $3 \mathrm{~b}$ represents the same functions but here excluding the three patients who failed to comply with instructions in the generation task. With all 11 cases included, success in generating the past-tense of both verb sets declined in relation to decreasing comprehension, but more steeply for the irregular verbs: the slopes of these functions calculated by regression analysis were 0.46 for regular and 0.79 for irregular. Although it was not predicted, this effect characterising the regular verbs for $N=11$ cases is not surprising, because the three patients who were unable to follow instructions included one with moderately impaired and two with severely impaired comprehension, and the past-tense generation errors of these three patients applied to regular as well as irregular verbs. The results from Fig. 3b provide a much better fit to our prediction. For the eight patients who could comply with the demands of the generation task, and whose synonym performance still covered a substantial range from $100 / 100$ down to $57 / 100$ correct, success in generating the past-tense of irregular verbs declined steeply as a function of comprehension (although at the higher end of comprehension, the decrease was not (a) $\mathrm{N}=\mathbf{1 1}$

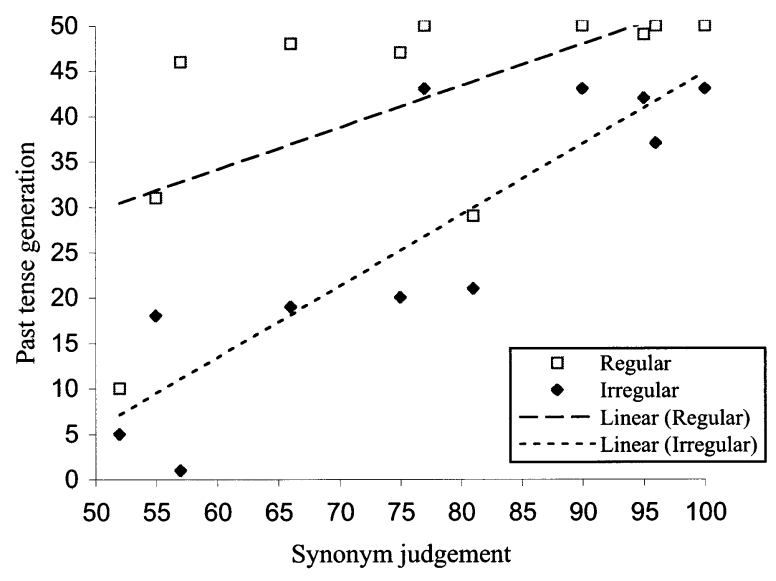

(b) $\mathbf{N}=\mathbf{8}$

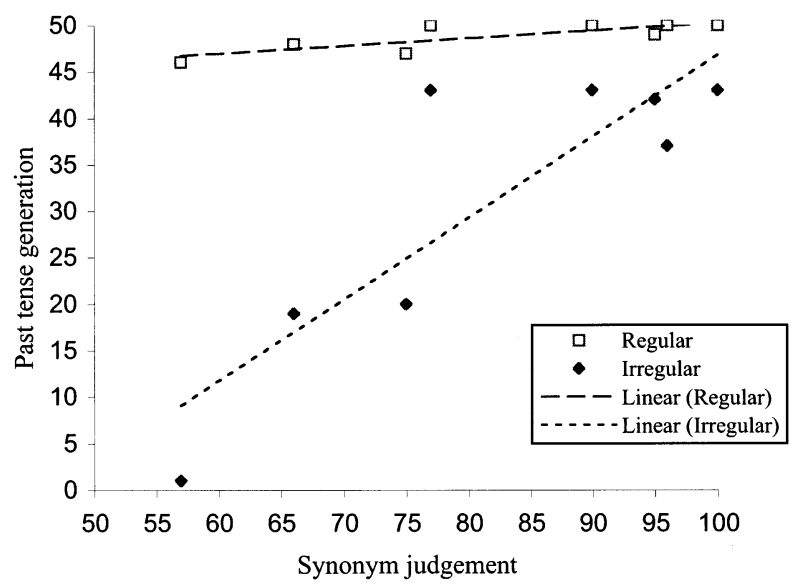

Fig. 3. (a) Past-tense generation scores (out of 50) for the regular and irregular verbs in the main set of stimulus items for each of the 11 patients as a function of his or her score (from 50 to 100) on the verb synonym judgement test; (b) The same plots for $N=8$ cases, excluding the three patients who failed to comply with instructions in the generation task

monotonic): the slope of this function is 0.88 . Success for regular verbs, by contrast, varied only slightly over the range of comprehension performance, slope $=0.08$. Furthermore, if past-tense performance is assessed with a difference score (for each patient in Fig. 3b, regular items correct minus irregular correct), there is a highly reliable relationship between verb comprehension and this difference measure $(r=$ $\left.0.87, r^{2}=0.75, t=4.24, P<0.01\right)$. This indicates that, as the degradation of meaning for these verbs worsens, the discrepancy between regular and irregular past-tense generation increases.

\subsubsection{Past-tense recognition in relation to synonym} judgements. Fig. 4 presents the relationship between 2AFC verb comprehension and $2 \mathrm{AFC}$ past-tense recognition, in the form of a $d^{\prime}$ analysis of discrimi- 
nation between correct and incorrect alternatives in both tasks. For synonym judgements, $d^{\prime}$ was calculated in the standard fashion, which is to take the $d^{\prime}$ score based on each patient's hit and false positive rates as in yes/no recognition, divided by a root 2 correction for 2AFC. The $d^{\prime}$ analysis for recognition of the past-tense was based on the following logic. Given that the great majority of English verbs form their past-tense by the addition of $-e d$, there should be a normal bias towards selecting the base + -ed alternative that was offered on every trial in the recognition task (as the correct alternative for regular verbs and as the incorrect foil for irregular verbs). On top of this bias, there should be item-specific knowledge influencing the subject's choice still further towards the -ed alternative for regular verbs, but in the opposite direction, towards the correct non -ed response, for the irregular verbs. We therefore calculated $d^{\prime}$ as a measure of discrimination by treating -ed choices for regular verbs as hits and -ed choices for irregular verbs as false positives, and then once again applying the root 2 correction for 2AFC. Fig. 4, which plots each patient's $d^{\prime}$ score for past-tense recognition against his or her $d^{\prime}$ score for synonym judgement $(N=10$ : recall that we were unable to collect past-tense recognition data from one patient), demonstrates a dramatic relationship $\left(r=0.93, r^{2}=\right.$ 0.87 , slope $=0.86, P<0.01$ ). As comprehension declined, the word-specific knowledge that is required to recognise the correct non -ed alternative for irregular verbs also declined, yielding an increasing false positive rate and a decreasing $d^{\prime}$.

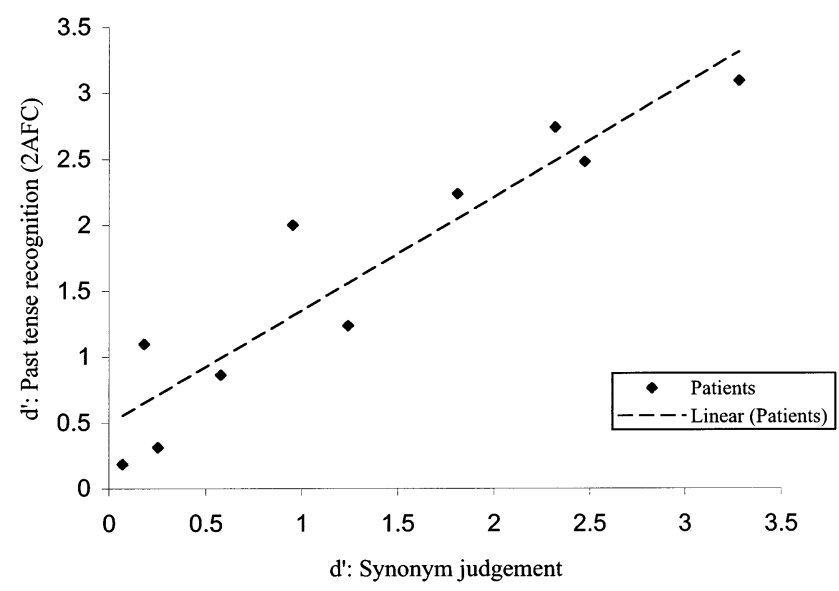

Fig. 4. A $d^{\prime}$ score for past-tense recognition (where hits = selection of the base $+-e d$ response for regular verbs and false positives $=$ selection of the base $+-e d$ response for irregular verbs) for each patient $(N=10)$ plotted as a function of his/her $d^{\prime}$ score on the synonym judgement test. Both $d^{\prime}$ scores have been divided by root 2 to correct for the $2 \mathrm{AFC}$ procedure.

\section{Discussion}

We have documented a selective and frequency modulated impairment in both generating and recognising the correct past-tense of irregular verbs in a case-series of patients with varying degrees of severity of semantic dementia. Prior to these data, there has been only limited behavioural evidence for a link between disrupted semantic knowledge and a specific deficit in knowledge of the irregular past-tense. A deficit restricted to irregular past-tense forms in patients with degraded semantic knowledge was predicted by Joanisse and Seidenberg [17] and simulated by these authors in a connectionist model that had no separate rule-governed and lexical-associative mechanisms. At the end of training, the Joanisse and Seidenberg network performed the present $\rightarrow$ past transformation accurately for essentially every verb in its vocabulary, and also generalised extremely well to novel verbs on which it had not been trained. This egalitarian treatment, however, hides distinctions in processing efficiency. Irregular verbs lack the shared connection-weight support enjoyed by regular verbs in the phonological input $\rightarrow$ output transformation of the intact network. As a result, even though the past-tense generation process activates both semantic and phonological representations for all verbs in the model's vocabulary, successful performance on irregular verbs comes to rely to a somewhat augmented degree on input from semantic representations. As predicted, disruption to the network's semantic component, which provides distinguishing information about individual words, had far more devastating consequences for irregular verbs than for regular or non-word items. With more extensive damage to semantics, the network's production of the past-tense of regular verbs also declined somewhat, to about $70 \%$ correct; but with this extent of lesioning, performance on the irregular forms was reduced to around $10-20 \%$ correct, thus yielding a substantial dissociation.

The results presented here are compatible with, and expand on, the predictions and results of Joanisse and Seidenberg's computational model. In the generation task, accuracy of the semantically-impaired patient group was characterised by significant effects of both verb frequency and past-tense regularity, plus a significant interaction between these two variables; the interaction arises from a disproportionate impairment on lower-frequency irregular items. For the whole group of patients $(N=11)$, accuracy was slightly subnormal on the regular items, too; but this was entirely attributable to three cases who could not or did not consistently produce past-tense responses as required by the task. Results for the generation task with these three patients excluded $(N=8)$ yielded a dramatic and frequency modulated deficit specific to irregular verbs: the propor- 
tions of correct responses for the lower frequency subsets were 0.96 for the regular verbs but only 0.53 for irregular. Errors in the generation task comprised mainly straightforward regularisations (adding -ed to a stem that should be turned into past-tense by some irregular transformation, e.g. responding think $\rightarrow$ 'thinked' rather than 'thought'); but there were also a significant number of errors (such as tear $\rightarrow$ 'tored' and slide $\rightarrow$ 'slode') that suggest partially retained knowledge of the way in which either the specific target verb or other irregular verbs form their past-tenses. In relation to cross-sectionally declining verb comprehension as measured by synonym judgements on the same verb set used in the past-tense tasks, there was a sharp decrement for irregular past-tense generation but a nearly flat function for the regular past-tense (Fig. 3b) and a marked reduction in the ability to recognise correct irregular forms (Fig. 4).

As discussed in the Section 1, the more traditional, two-mechanism theory of inflectional morphology $[16,24,31,41]$ holds that regular past-tense forms like blinked have no independent lexical representation but are generated by grammatical rule from the stem blink. Irregular pasts like drank and thought, which cannot be generated by rule from drink and think, must be listed in the lexicon. From this perspective, the natural interpretation of patients like the ones described here, who succeed in generating and recognising regular forms but frequently fail on the irregulars, is that they have a lexical deficit but an intact rule system. Joanisse and Seidenberg [17] commented that 'the past-tense debate has continued for about 10 years without resolution because most of the behavioural data can be accommodated by both theories' (p. 7593). In keeping with this assessment, we acknowledge that much of the pattern of data presented here is also congruent with both approaches. We shall highlight the three aspects of our data that motivate our continuing efforts to develop a complete parallel-distributed processing-based account. While these facts might be accommodated within some version of the traditional two-mechanism approach, they seem to us to be clearly consistent with the characteristics of the PDP/constraint-satisfaction approach.

As noted in Section 3.2.2, the two-mechanism theory would expect an impaired lexical associative mechanism to yield a preponderance of regularisation errors in the past-tense generation task, since the patient would be forced to rely on the alternative rule-governed procedure. The observed high rate of regularisation errors therefore fails to discriminate between the two accounts. More telling, in our view, are the errors that combine regular and irregular elements ('part regularisations' such as tear $\rightarrow$ 'tored' and freeze $\rightarrow$ 'frozed') and those that suggest some general aspects of retained knowledge of the way in which irregular verbs form their past-tenses (including vowel alternation errors such as slit $\rightarrow$ 'slat', and no-change errors such as grind $\rightarrow$ 'grind' which occurred almost uniquely on verbs whose present-tense forms already end in $/ t /$ or /d/). These 'mixed' errors were less common than pure regularisations, but constituted a sizeable $23 \%$ of incorrect responses to irregular verbs for the patients $(N=8)$ who complied with instructions in the past-tense generation task.

A tendency for the processing of irregular verbs to exhibit sensitivity to aspects of the regular pattern - in the production of blends of the regular inflection with knowledge of exceptions and also no change responses to stems that already end in $/ \mathrm{t} /$ or $/ \mathrm{d} /$ - was demonstrated by Rumelhart and McClelland's PDP model of past-tense learning [35]. While we do not mean to suggest that no account of such errors could be given within the dual-mechanism approach, it is not obvious how they would arise. Consider, for example, an error like 'tored'. In the theory developed by Pinker [31], the availability of a response based on the lexical mechanism is thought to block application of the rule. In that case, one might ask: on those occasions when this mechanism is working well enough to yield 'tore' as the past of tear, why does the rule mechanism still add its voice to give mixed errors such as 'tored'?

Secondly, the suggestion in our results that the level of impairment on different types of irregular verbs (vowel change, terminal consonant change, etc.) may be graded by degree of similarity to regular forms also seems more in keeping with a system that has encoded both regular and exceptional exemplars in the same network. As we have noted, our study was not designed to address the impact of the different ways in which irregular verbs are transformed to form the past-tense; this aspect of the results must therefore be treated as a hypothesis and subjected to further empirical test. We do not, however, detect any clear basis in the dualmechanism theory on which to predict differential success amongst subsets of irregular verbs based on similarity to the regular pattern: all irregular verbs are thought to be generated by the lexical/associative mechanism, and not to be influenced during processing by application of the past-tense rule.

Finally, there is our finding - clearly consonant with the PDP framework - that a patient's degree of deficit on irregular verbs was strongly predicted by his or her performance in the synonym judgement task. Pinker's description of the language system suggests that lexical entries or roots must be separate from semantic representations (e.g. [31], pp. 41-42), in which case it is not obvious why a dual-mechanism theory would predict a reliable association between semantic degradation and irregular past-tense deficit. It should be noted, however, that Ullman et al. [41,42] have accommodated earlier evidence of such an association by asserting that semantic and lexical representations 
depend on a common declarative memory system located within temporal lobe structures. It thus appears that the two-mechanism account is flexible with respect to the possible association between semantic impairment and poor performance on the irregular past-tense. In contrast, there are no separate lexical representations in the PDP theory; rather, semantic representations serve the role played by lexical representations in the traditional theory. Impaired performance on the irregular past-tense by patients with semantic dementia is therefore an intrinsic prediction of our approach.

The PDP/constraint-satisfaction account of impaired performance for irregular past-tense verbs is precisely parallel to the explanation from this same perspective for a selective, frequency-modulated impairment in reading aloud words with irregular spelling-sound correspondences (e.g. [27,29,32]) and in writing dictated words with unpredictable sound-spelling correspondences [9] - disorders typically referred to as surface dyslexia and dysgraphia. In this context, it seems important to note that, whereas we have only presented data here from tasks that involve past-tense verb processing, the same patients who participated in this study have been assessed on tasks of single-word oral reading and spelling to dictation, and all of the patients were both surface dyslexic and dysgraphic. Poorest performance always occurred on the low-frequency irregular words, to which the predominant error type was a regularisation (e.g. reading aloud pint to rhyme with 'mint', or spelling 'cough' $\rightarrow$ coff), just as in the pasttense generation task.

In summary, several aspects of our results conform to predictions that arise from the PDP approach. It must be noted, however: (a) that additional modelling work is needed to confirm that implemented PDP networks can in fact capture all of these aspects of the data; and (b) that further modification or elaboration of the two-mechanism approach might also result in a version that accounts for our results. Furthermore, we acknowledge that the study reported here has dealt only with one side of the reported double dissociation for verb morphology: a convincing argument in favour of the constraint-satisfaction approach will of course also require an account of patients with an advantage for irregular over regular past-tense verbs (reported in $[24,25,41,42])$. Such a pattern has not yet been convincingly demonstrated or explained within the PDP framework. We take this challenge seriously, and we are pursuing experiments on relevant patient groups and additional computational modelling studies in an effort to address it. Specifically, we are currently exploring the hypothesis that a disadvantage for regular past-tense forms might result from a phonological deficit. Related ideas have been previously introduced by Leonard [21] and Hoeffner and McClelland [14] to account for a similar pattern observed in language-impaired children.
Finally, to return to verb deficits in semantic dementia, we should briefly address the issue of why these patients essentially never make errors on past-tense irregular verbs in their spontaneous speech. In our view, the surprise would be if they did make such mistakes rather than the fact that they do not. These patients have a severely reduced and longititudinally diminishing vocabulary for speech production. With disease progression, their speech contains fewer and fewer specific content words; both specific nouns and verbs are increasingly replaced by very common, general terms: high-frequency pronouns for people's names, words like 'thing' and 'place' for nouns, 'make' and 'do' for many verbs [1]. We attribute this vocabulary loss to an increasingly degraded semantic system that cannot provide sufficiently detailed information to activate phonological representations for more specific, and lower-frequency, content words. Where a patient has enough conceptual knowledge regarding a particular verb to activate its phonological representation at all, we argue that he or she will likely have enough semantic information to enable production of the correct past-tense. The nouns (like 'thing') and verbs (like 'make') that do pepper the patients' speech are essentially always correctly inflected for number and tense.

In fact, we have very occasionally seen irregular past-tense errors in the patients' self-generated speech, but only in conversational situations that rather resemble the verb generation paradigm, because the questioner just happens to have supplied the present-tense form of the verb. Two recent observations of this phenomenon from patients in this study are: (i) when an examiner, chatting to DM about his travels, asked "Did you fly directly to Australia", and he replied, "Yes, I flied there"; and (ii) when someone asked IF "When did you go to London?" and he answered "I goed to London yesterday".

\section{Acknowledgements}

We are grateful for enlightening discussions of the issues and/or helpful comments on the original version of the manuscript from Helen Bird, Marc Joanisse, David Plaut and Mark Seidenberg.

\section{References}

[1] Bird H, Lambon Ralph MA, Patterson K, Hodges JR. The rise and fall of frequency and imageability: noun and verb production in semantic dementia. Brain and Language 2000;73:17-49.

[2] Bozeat S, Lambon Ralph MA, Patterson K, Garrard P, Hodges JR. Non-verbal impairment in semantic dementia. Neuropsychologia 2000;38:1207-15.

[3] Breedin SD, Saffran EM. Sentence processing in the face of semantic loss: a case study. Journal of Experimental Psychology: General 1999;128:547-62. 
[4] Bybee JL, Moder CL. Morphological classes as natural categories. Language 1983;59:425-55.

[5] Chertkow H, Bub D. Semantic memory loss in dementia of Alzheimer's type. Brain 1990;113:397-417.

[6] Coltheart M. The MRC psycholinguistic database. Quarterly Journal of Experimental Psychology 1981;33A:497-505.

[7] Francis WN, Kucera H. Frequency Analysis of English Usage: Lexicon and Grammar. Boston: Houghton-Mifflin, 1982.

[8] Funnell E. Objects and properties: a study of the breakdown of semantic memory. Memory 1995;3:497-518.

[9] Graham NL, Patterson K, Hodges JR. The impact of semantic memory impairment on spelling: evidence from semantic dementia. Neuropsychologia 2000;38:143-63.

[10] Harm MW, Seidenberg MS. Phonology, reading acquisition, and dyslexia: insights from connectionist models. Psychological Review 1999;106:491-528.

[11] Hodges JR, Graham N, Patterson K. Charting the progression in semantic dementia: implications for the organisation of semantic memory. Memory 1995;3:463-95.

[12] Hodges JR, Patterson K. Is semantic memory consistently impaired early in the course of Alzheimer's disease? Neuroanatomical and diagnostic implications. Neuropsychologia 1995; $33: 441-59$

[13] Hodges JR, Patterson K, Oxbury S, Funnell E. Semantic dementia: progressive fluent aphasia with temporal lobe atrophy. Brain 1992;115:1783-806.

[14] Hoeffner JJ, McClleland JL. Can a perceptual processing deficit explain the impairment of inflectional morphology in developmental dysphasia? A computational investigation, In: Clark E (editor), Proceedings of the 25th Annual Child Language Forum. Stanford CA: Center for the Study of Language and Information, 1993: pp. 38-49.

[15] Howard D, Patterson K. Pyramids and Palm Trees: A Test of Semantic Access from Pictures and Words. Bury St Edmunds: Thames Valley Test Company, 1992.

[16] Jaeger JJ, Lockwood AH, Kemmerer DL, Van Valin RD, Murphy BW, Khalak HG. A positron emission tomography study of regular and irregular verb morphology in English. Language 1996;72:451-97.

[17] Joanisse MF, Seidenberg MS. Impairments in verb morphology after brain injury: a connectionist model. Proceedings of the National Academy of Sciences 1999;96:7592-7.

[18] Kaskie B, Storandt M. Visuospatial deficit in dementia of the Alzheimer type. Archives of Neurology 1995;52:422-5.

[19] Kucera H, Francis WN. Computational Analysis of Present-Day American English. Providence, RI: Brown University Press, 1967.

[20] Lambon Ralph MA, McClelland JL, Patterson K, Galton CJ, Hodges JR. No right to speak? The relationship between object naming and semantic impairment: neuropsychological evidence and a computational model, Journal of Cognitive Neuroscience, In press.

[21] Leonard L. Language learnability and specific language impairment in children. Applied Psycholinguistics 1989;10:179-202.

[22] MacWhinney B, Leinbach J. Implementations are not conceptualizations: revising the verb learning model. Cognition 1991;40:121-57.

[23] McClelland JL, Rumelhart DE. An interactive activation model of context effects in letter perception: part 1. An account of basic findings. Psychological Review 1981;88:375-407.
[24] Marslen-Wilson WD, Tyler LK. Dissociating types of mental computation. Nature 1997;387:592-4.

[25] Marslen-Wilson WD, Tyler LK. Rules, representations, and the English past tense. Trends in Cognitive Sciences 1998;2:428-35.

[26] Mummery CJ, Patterson K, Price CJ, Ashburner J, Frackowiak RSJ, Hodges JR. A voxel-based morphometry study of semantic dementia: the relationship of temporal lobe atrophy to cognitive deficit. Annals of Neurology 2000;47:36-45.

[27] Patterson K, Hodges JR. Deterioration of word meaning: implications for reading. Neuropsychologia 1992;30:1025-40.

[28] Patterson K, Hodges JR. Semantic dementia: one window on the structure and organisation of semantic memory. In: Cermak L, editor. Handbook of Neuropsychology: Memory Disorders. Amsterdam, London: Elsevier, 2000:289-309.

[29] Patterson K, Lambon Ralph MA. Selective disorders of reading? Current Opinion in Neurobiology 1999;9:235-9.

[30] Pinker S. Rules of language. Science 1991;253:530-5.

[31] Pinker S. Words and Rules: The Ingredients of Language. London: Weidenfeld and Nicolson, 1999.

[32] Plaut DC, McClelland JL, Seidenberg MS, Patterson K. Understanding normal and impaired word reading: computational principles in quasi-regular domains. Psychological Review 1996;103:56-115.

[33] Plunkett K, Marchman V. U-shaped learning and frequency effects in a multi-layered perceptron: implications for child language acquisition. Cognition 1991;38:43-102.

[34] Plunkett K, Nakisa RC. A connectionist model of the Arabic plural system. Language and Cognitive Processes 1997;12:80736.

[35] Rumelhart DE, McClelland JL. On learning the past tenses of English verbs. In: McClelland JL, Rumelhart DE, editors. Parallel Distributed Processing, vol. 2. Cambridge Mass: MIT Press, 1986:216-71

[36] Seidenberg MS. Connectionism without tears. In: Davis S, editor. Connectionism: Advances in Theory and Practice. Oxford: OUP, 1992:84-137.

[37] Seidenberg MS, McClelland JL. A distributed, developmental model of word recognition and naming. Psychological Review 1989;96:523-68.

[38] Snodgrass JG, Vanderwart M. A standardized set of 260 pictures: norms for name agreement, familiarity and visual complexity. Journal of Experimental Psychology: Learning Memory and Cognition 1980;6:174-215.

[39] Snowden JS, Goulding PJ, Neary D. Semantic dementia: a form of circumscribed cerebral atrophy. Behavioural Neurology 1989;2:167-82.

[40] Snowden JS, Neary D, Mann DMA. Fronto-temporal Lobar Degeneration: Fronto-temporal Dementia, Progressive Aphasia, Semantic Dementia. New York: Churchill Livingstone, 1996.

[41] Ullman MT, Corkin S, Coppola M, Hickok G, Growdon JH, Koroshetz WJ, Pinker S. A neural dissociation within language: evidence that the mental dictionary is part of declarative memory, and that grammatical rules are processed by the procedural system. Journal of Cognitive Neuroscience 1997;9:266-76.

[42] Ullman MT, Izvorski R, Love T, Yee E, Swinney D, Hickok G. Neural correlates of lexicon and grammar: evidence from the production, reading and judgment of inflection in aphasia, Brain and Language, In press.

[43] Warrington EK, McKenna P, Orpwood L. Single word comprehension: a concrete and abstract word synonym test. Neuropsychological Rehabilitation 1998;8:143-54. 